\title{
Design of a Certain Type of Radar Maintenance Training System Software
}

\author{
Han-ao Xia, Dao-ju Duan, Zhong-hua Zhang \\ Radar Department \\ Wuhan ordnance Non-commissioned Officer Academy of PLA \\ Wuhan, China
}

\begin{abstract}
According to the demands of opening, universality and modularity criterion in radar equipment Maintenance Training System (MTS), we developed a model radar MTS software system, this software system consisted of system buildup module, maintenance training module, fault database module and maintenance assistant module. This software can be used to do maintenance training for some model radar. This software system has been applied in a maintenance training for some model radar.
\end{abstract}

Keywords-maintenance training; software design; radar.

\section{INTRODUCTION}

As the eyes of the battlefield, radar equipments were configured in varieties of integrated weapon system, once the equipments working failed, they would need maintenance staff in urgent. The radar equipment maintenance and support staff training relies on the radar equipment, due to the limited number of the corresponding types of radar and thus the training efficiency greatly discounted. In order to improve the efficiency of radar maintenance training, it is necessary to develop the radar maintenance training system. Therefore, we developed a certain type of radar maintenance training system software. Through the analysis of the existing fault case, collation, analysis and summary of the correspondence between of radar fault and fault points, the system formed fault database and fault matrix.

\section{SYSTEM SCHEME}

The software of a certain type of radar maintenance training system (MTS) includes four parts: system build-up module, maintenance training module, fault database module and maintenance assistant module. The maintenance training module is the main content of the system development. The top level design of MTS software platform is shown in Figure 1.

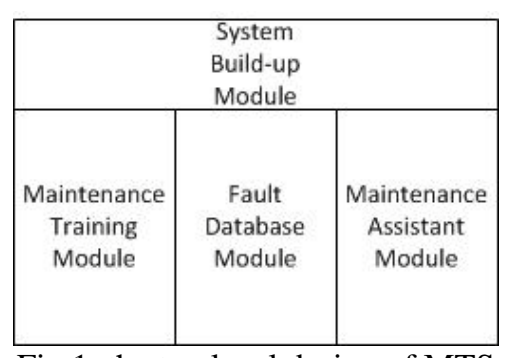

Fig.1. the top level design of MTS
MTS software platform adopts the layered mode to realize the open system architecture. The whole software platform contains the user interface layer, core layer, module communication layer. The user interface layer mainly completes the interaction of the user between the system, including the dialog box, menu, toolbar, shortcut keys and the command button, etc. Core layer is the basis of stable and reliable operation of MTS software, which is composed of event mechanism, fault database, running engine and some public service. The module communication layer is used to complete the transmission and processing of messages in the core layer of each functional module.

\section{THE DEVELOPMENT OF MTS SOFTWARE}

The system is designed and operated on Win8.1 platform, we chose the Microsoft company's Visual Basic as the development platform for MTS software. MTS software mainly consists of four parts: system build-up module, maintenance training module, fault database module and maintenance assistant module. The main program interface of the system is shown in Figure 2.

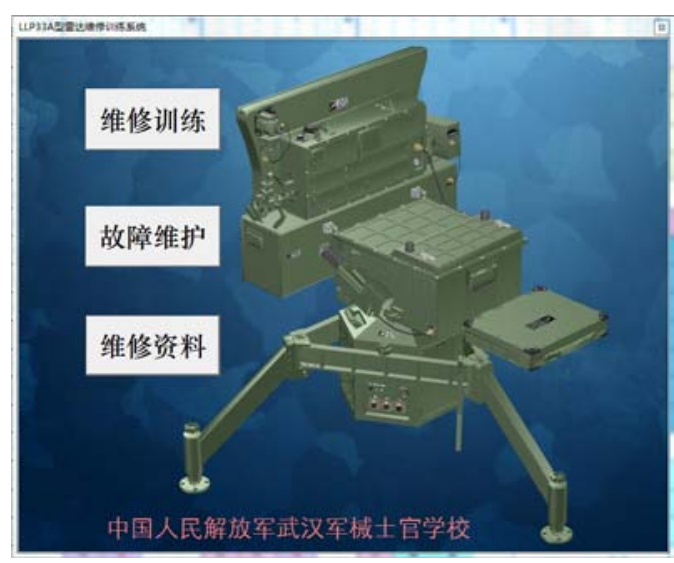

Fig.2. the main program interface of MTS

\section{A. Maintenance training module}

The maintenance training module is based on a certain type of radar maintenance manual, using fault module, fault phenomenon or self-test information for fault analysis and judgment, according to the logic relationship between the the fault point and fault phenomenon or self-test information for a maintenance strategy, the maintenance training module interface is shown in figure 3. 


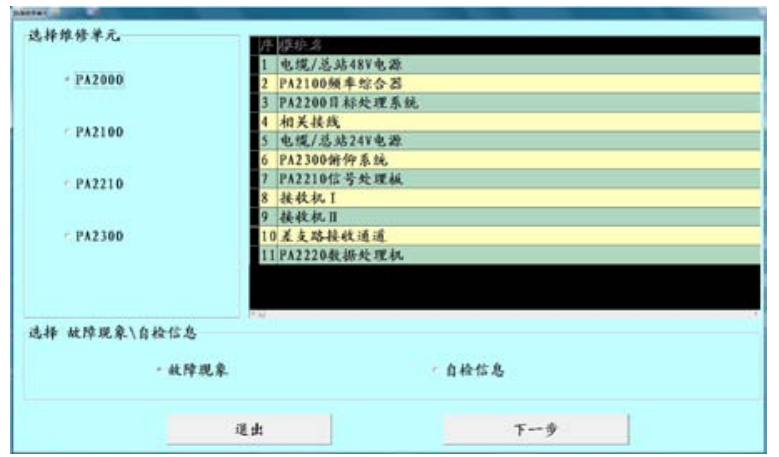

Fig.3. the interface of maintenance training module

In the maintenance training module, we can select the relevant fault module to do maintenance training as figure 3 shows, and select the option "fault phenomenon" to enter into the maintenance training as figure 4 shows, or select the option "self-test information" to enter into the maintenance training as figure 5 shows.

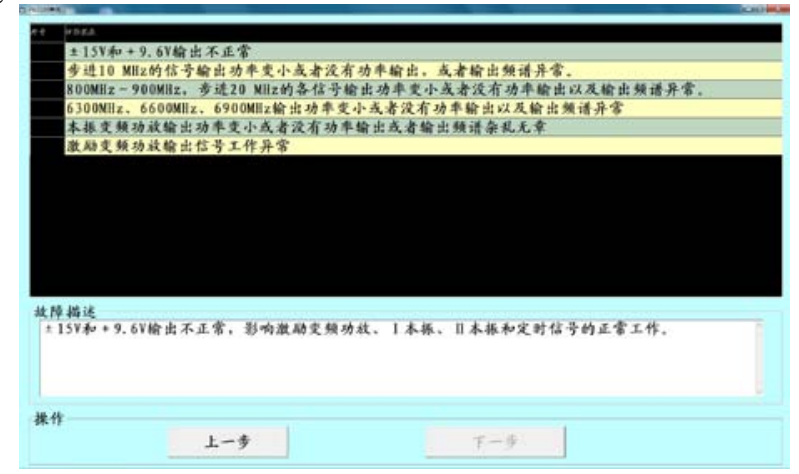

Fig.4. the interface of fault phenomenon in the maintenance training module

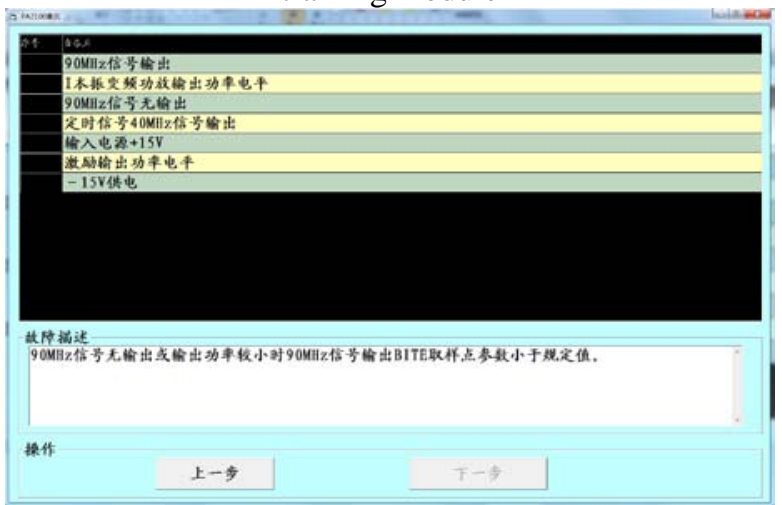

Fig.5. the interface of self-test information in the maintenance training module

After choosing the relevant fault phenomenon or self-test information, we can enter into the operating guide prompting maintenance operations in the way of pictures or texts. The interface of operating guide in the maintenance training module is shown in Figure 6.

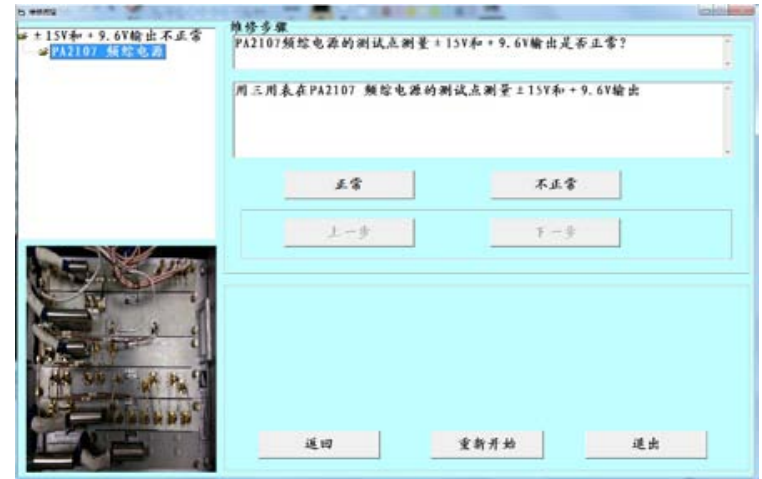

Fig.6. the interface of operating guide in the maintenance training module

\section{B. Fault database module}

The fault database module is based on a certain type of radar maintenance manual, using fault module, fault phenomenon or self-test information for fault analysis and judgment, according to the fault phenomenon or the relationship between the fault point and the logic relationship between the formation of fault diagnosis strategy to generate the fault database. In this module, we can add, modify and delete the fault module, fault phenomenon, self-test point information and test method. The module interface is shown in figure 7 .

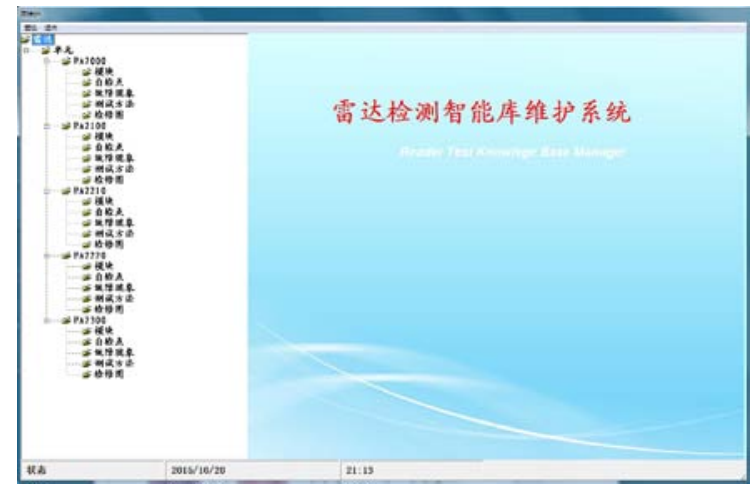

Fig.7. the interface of fault database module

For example, we can add, modify and delete the fault phenomenon to the relevant fault modules as figure 8 and figure 9 shows.

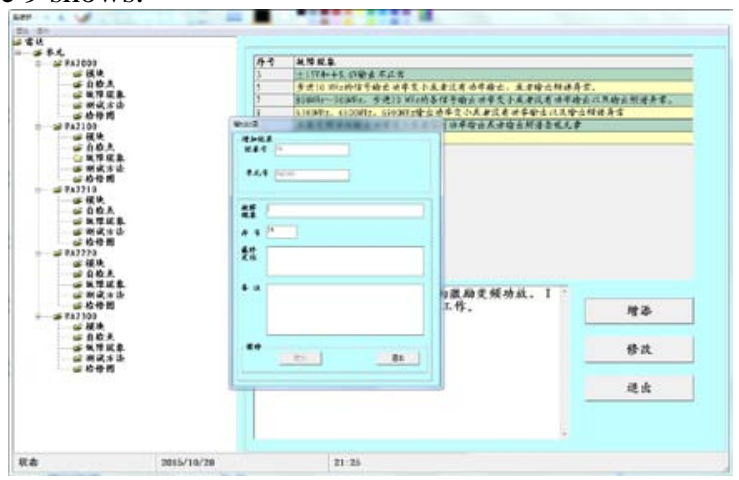

Fig.8. the interface of adding fault phenomenon in the fault database module 


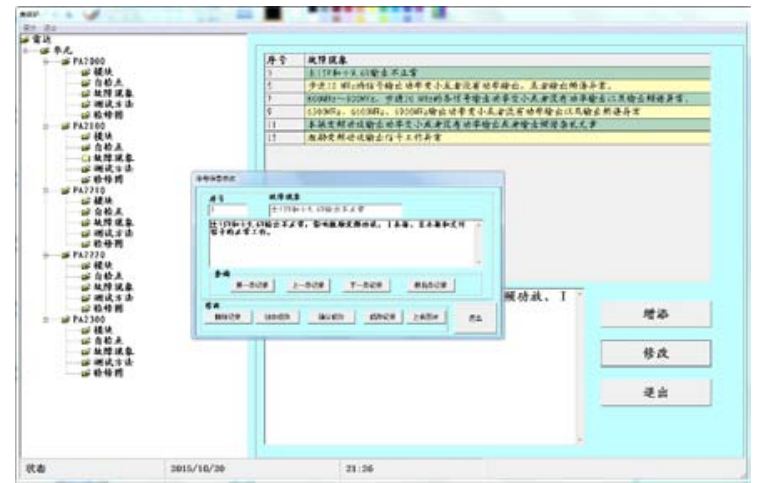

Fig.9. the interface of modifying or deleting fault phenomenon in the fault database module

\section{Maintenance assistant module}

This maintenance assistant module which has some guidance is based on the failure cases of the equipment, the technical data of the manufacturer, the army survey and the normal maintenance teaching and training. The maintenance information is presented in the form of PDF electronic document, which is embedded in the maintenance training system. It is convenient for inspection in the process of maintenance and training. The module interface is shown in figure 10 .

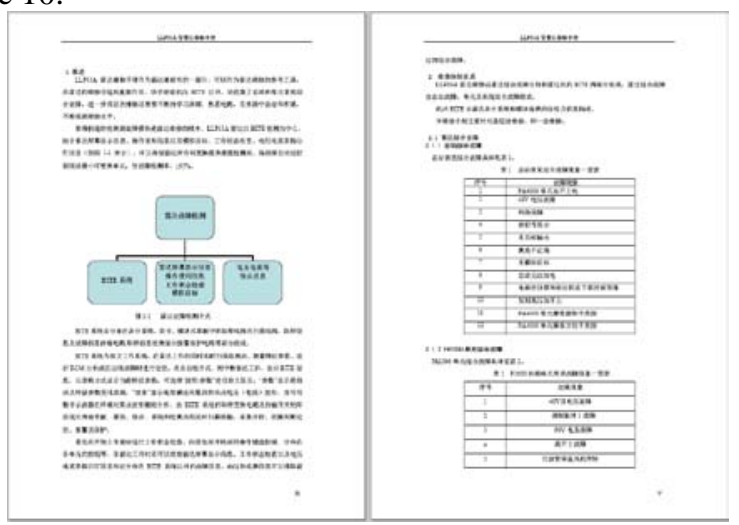

Fig.10. the interface of maintenance assistant module

\section{CONCLUSION}

The software of a certain type of radar maintenance training system is transplanted to many kinds of radar maintenance training system through the development of different radar fault cases. Through this system, we can reduce the dependence on radar equipment, realize the low cost and high efficiency of radar maintenance training to study the radar principle, structure, circuit, maintenance and other aspects of training, it can assists in the field of radar equipment repair and maintenance.

\section{REFERENCES}

[1] Li Hangshan, Zuo Yi, Sun Jie. Automatic testing Integrated technology [M]. Beijing: Electronic Industry Press, 2004.

[2] Qin Honglei, Lu Hui, Lang Rongling. Automatic test system - hardware and software technology [M]. Beijing: Higher Education Press, 2007.

[3] Liu Qi, He Yuzhu. Design of electronic measurement technology based on the general MTS software [J]. Electronic Measurements Technology, 2012.12:46-49.

[4] Guo Sumin, Xu Kebao, Wu Bo. Design of General automatic test system based on component technology [J]. Computer Measurement and Controlm, 2013.21 (10): 2859-2861.

[5] Du Zhanlong, Tan Yeshuang. Design and implementation of automatic test system software platform [J] Measurement and Control Technology, 2012.04:96-99.

[6] Chen Kunzhong. Research and application of software framework for automatic test system [D]. Beijing: Beijing University of Aeronautics and Astronautics, 2006 